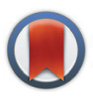

CrossMark

$\leftarrow$ click for updates

Cite this: Dalton Trans., 2015, 44 6313

Received 16th January 2015,

Accepted 24th February 2015

DOI: $10.1039 / c 5 d t 00210 a$

www.rsc.org/dalton

\section{Dynamic structure elucidation of chemical reactivity by laser pulses and X-ray probes $\uparrow$}

\author{
Stuart A. Bartlett, ${ }^{a, b}$ Michelle L. Hamilton ${ }^{a, c, d}$ and John Evans ${ }^{\star a, e, f}$ \\ Visualising chemical reactions by $\mathrm{X}$-ray methods is a tantalising prospect. New light sources provide the \\ prospect for studying atomic, electronic and energy transfers accompanying chemical change by $\mathrm{X}$-ray \\ spectroscopy and inelastic scattering. Here we assess how this adventure can illuminate inorganic and \\ catalytic chemistry. In particular X-ray inelastic scattering provides a means of exploiting X-ray free elec- \\ tron lasers, as a parallel to laser Raman spectroscopy.
}

\section{Introduction}

Visualising chemical reactions is indeed a tantalising prospect. An excellent illustration of this is the light-induced insulatormetal transition of the organic salt, (EDO-TTF) $)_{2} \mathrm{PF}_{6}$, (EDO-TFF = ethylenedioxytetrathiafulvalene) investigated using an ultrabright femtosecond electron source on a crystalline sample. ${ }^{1}$ An organic metal was formed after a thin crystal of the organic salt was illuminated with $800 \mathrm{~nm}$ near infra-red light. The electron diffraction pattern of the insulating phase changed showing that some unit cells of the conducting structure phase were formed within 10-15 ps, and evidence found for the atomic displacements occurring in the first few ps.

Deriving similar type of information about the primary steps of the reactions or electron movement within inorganic complexes, compounds and materials would revolutionise our understanding of this field of chemistry. Some years ago, we reviewed the developing opportunities for the use of time resolved X-ray absorption fine structure (XAFS) spectroscopy for structure-reactivity studies in chemistry. ${ }^{2}$ (XAFS spectra consist of XANES, X-ray absorption near edge structure, and EXAFS, extended X-ray absorption fine structure, regions.) Since then projected developments in X-ray sources ${ }^{3}$ are in the

\footnotetext{
${ }^{a}$ Research Complex at Harwell, Rutherford Appleton Laboratory, Didcot, OX11 OFA, $U K$

${ }^{b}$ Department of Chemistry, University of Bath, Bath, BA2 7AY, UK.

E-mail: stuart.bartlett@rc-harwell.ac.uk

${ }^{c}$ School of Chemistry, University of Nottingham, Nottingham, NG7 2RD, UK.

E-mail: michelle.hamilton@rc-harwell.ac.uk

${ }^{d}$ RAL Space, Rutherford Appleton Laboratory, Didcot, OX11 OQX, UK

${ }^{e}$ Chemistry, University of Southampton, Southampton, SO17 1BJ, UK.

E-mail: je@soton.ac.uk

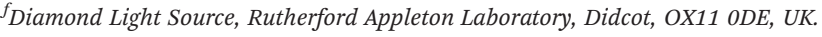

E-mail:john.evans@diamond.ac.uk

$\dagger$ Dedicated to Professor Ken Wade, in memory of his chemical imagination, his leadership, and his humour.
}

process of being realised and these are transforming the scope of in situ structure elucidation. In this article we assess what is now possible and what may become feasible over the next few years.

Over the last 100 years, since the report by Bragg, ${ }^{4} \mathrm{X}$-ray diffraction has been pivotal in developing our understanding of chemical structure. It remains the database of reference structures upon which reaction studies in non-crystalline media are calibrated. In this article we focus on investigating the structures of solutions using X-ray absorption fine structure (XAFS) spectroscopy, and techniques derived from it, as the probe.

\section{Structure determination using XAFS}

The first observations of an element's X-ray absorption edge by de Broglie ${ }^{5}$ and the correlation of the energies of X-ray emissions to the Periodic Table by Moseley ${ }^{6}$ were almost coincident with that of diffraction from crystals. ${ }^{4}$ Chemical shifts in absorption edge energies were established within a few years, and near-edge structure reported in 1920 by Fricke. $^{7}$ Over many years, there was uncertainty as to whether XAFS was due to long range order, as for diffraction, or due to local effects. This was resolved by Stern in 1974 as being a local effect, ${ }^{8}$ thus providing a new structural technique applicable to disordered materials, including solutions, glasses and catalyst surfaces. Once synchrotron radiation provided X-ray sources of the required intensity (generally to get the signal/noise ratio of $10^{5}$, at least $10^{10}$ monochromatic photons are required to impinge on the sampled area), XAFS could then be applied to a range of chemical problems. This requirement is illustrated in Fig. 1. Relative to the start of the EXAFS region, which is visible in the XAFS spectrum, the end of the EXAFS region is weighted by a factor of over 700 . With current, third generation 

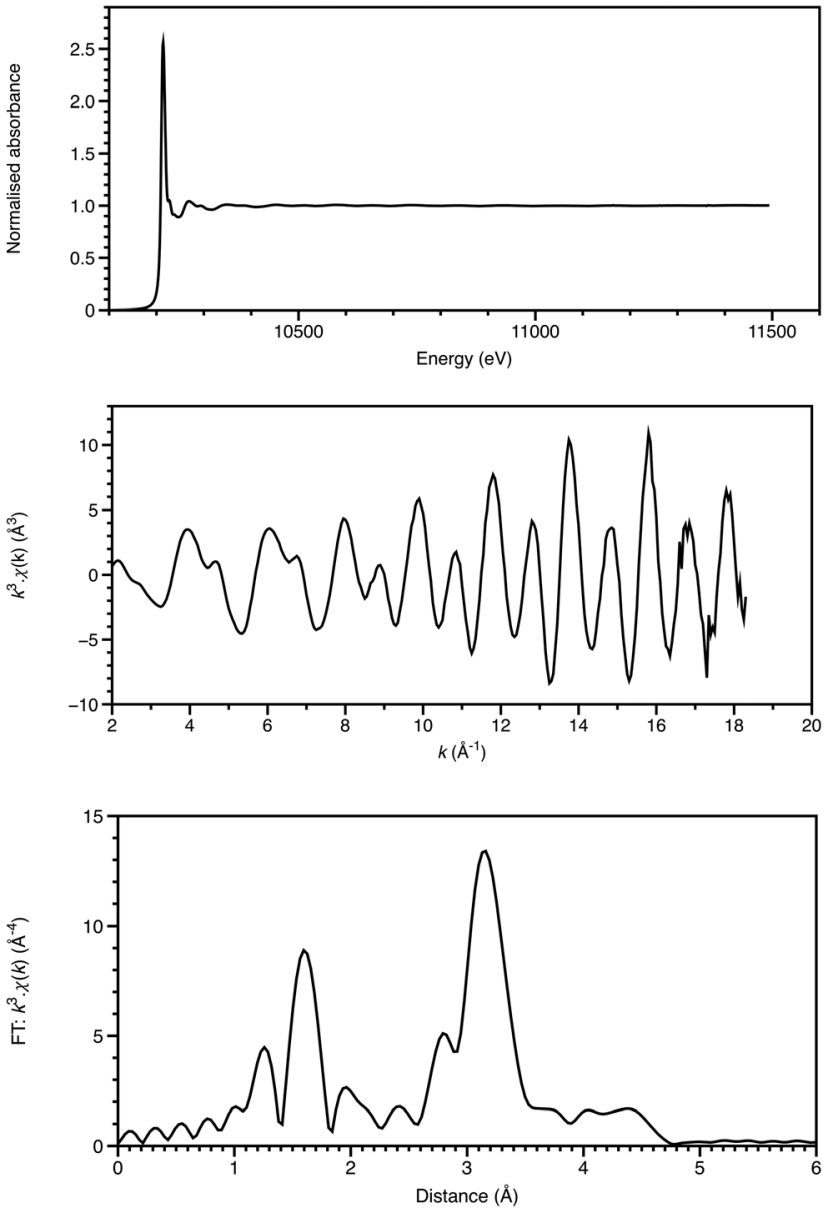

Fig. $1 \mathrm{~W} \mathrm{~L}_{1 \mid 1}$-edge XAFS of $\left(\mathrm{NBu}_{4}\right)_{2}\left[\mathrm{~W}_{6} \mathrm{O}_{19}\right]$ showing the normalised absorption spectrum (top), the $k^{3}$-weighted EXAFS (middle) and the Fourier transform (bottom). Data recorded on B18 of the Diamond Light Source.

sources, such a photon count can be achieved in a focussed (sub $\mathrm{mm}$ ) spot in the order of $10 \mathrm{~ms}$, and for an X-ray free electron laser, in a single pulse of $20-100$ fs. Spectra like this (Fig. 1a), with a $1600 \mathrm{eV}$ range, can be acquired in seconds or minutes.

Analysis of the extended X-ray absorption fine structure (EXAFS) is well established, ${ }^{9}$ and, depending upon the system, may provide structural detail within 3-5 $\AA$ of the absorbing atom (Fig. 1). Single-scattering modelling affords interatomic distances from the absorber, but some bond-angle information is intrinsic to more sophisticated analyses including multiple scattering pathways. This is often essential for a proper analysis, and provides a local cluster structural model.

The features of X-ray absorption near edge structure (XANES) are very sensitive to the coordination geometry, ligand type and spin state of the absorbing atom. Thus they probe the effects of the coordination site on the electronic properties around the absorbing atom. The discrimination of XANES has now been enhanced by utilisation of crystal analysers for X-ray emission spectroscopy (XES) in the following ways (Fig. 2).
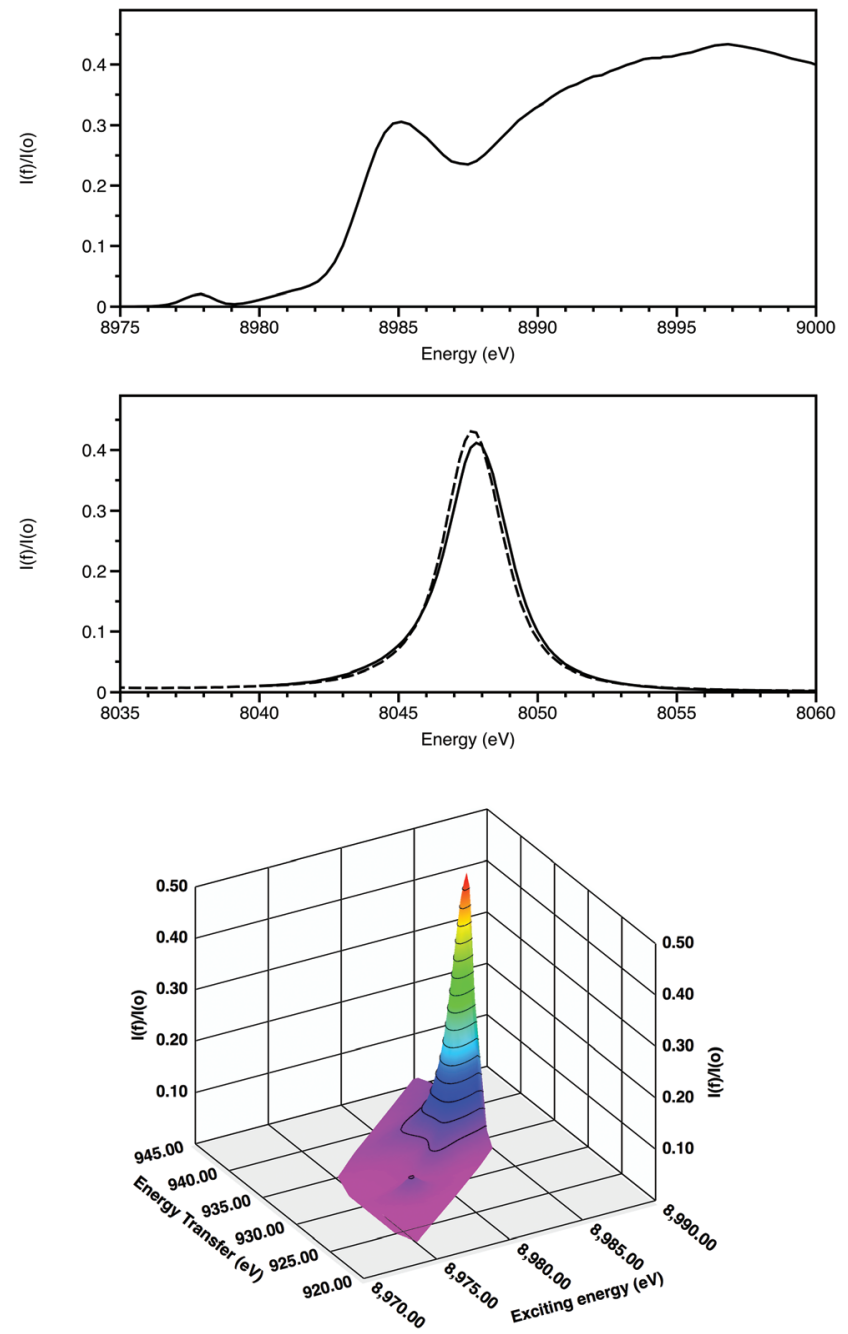

Fig. $2 \mathrm{Cu}$ K-edge XANES of CuO showing the HERFD spectrum (top), $\mathrm{K} \alpha_{1}$ emission spectra of $\mathrm{CuO}$ (solid) and $\mathrm{Cu}$ (dashed) with the exciting energy above the absorption edge (middle) and K $\alpha_{1}$ RIXS (bottom). Energy transfer = Exciting energy - emission energy. Data recorded on 120 of the Diamond Light Source.

(i) High energy-resolution fluorescence detection (HERFD) resolves features within the XANES. ${ }^{10}$ Firstly this is achieved by monitoring a single channel rather than multiple overlapping ones and, secondly, when following an inelastic scattering process, the core hole lifetime broadening of relevance for $\mathrm{K} \alpha$ is for $2 \mathrm{p}$ rather than $1 \mathrm{~s}$ ( 0.6 rather than $1.6 \mathrm{eV}$ ).

(ii) 2-dimensional maps of absorption and emission features, termed Resonant Inelastic X-ray scattering (RIXS provide greater chemical speciation. ${ }^{11}$ Here (Fig. 2) the weak $3 \mathrm{~d} \mathrm{~K} \alpha_{1}$ resonance is clearly separated from the higher energy dipoleallowed transitions to $4 \mathrm{p}$ and also to the continuum. The excited state after the RIXS process for $\mathrm{CuO}$ has a configuration $2 \mathrm{p}^{5} 3 \mathrm{~d}^{10}$. Splitting due to spin-orbit coupling is only within the incomplete $2 \mathrm{p}$ sub-shell. As a result, this resonance is a doublet, with the second component associated with the $\mathrm{K} \alpha_{2}$ emission line displaced from the $\mathrm{K} \alpha_{1}$ features by $20 \mathrm{eV}$. 
Full multiple scattering $\operatorname{codes}^{12,13}$ and density functional methods $^{14,15}$ can, in many cases, provide a good basis for modelling XANES, ${ }^{16,17}$ XES $^{17,18}$ and RIXS. ${ }^{19}$ Theoretical structure modelling and spectrum simulation are now closely linked, ${ }^{20}$ and, together with EXAFS structural analysis, afford an iteration cycle. ${ }^{18,21,22}$ Hence this combination of X-ray spectroscopy, analysis, and theoretical modelling forms a substantial basis for probing chemical reactivity and providing greater understanding of the electronic structure of the absorbing element.

\section{Kinetics and dynamics of reactions}

The rates of reactions of inorganic systems span a vast timescale. Even restricting the survey to water exchange rates of hexaaqua complexes for divalent $3 \mathrm{~d}$ metal ions, still provides a range of rate constants between $87 \mathrm{~s}^{-1}\left(\mathrm{~V}^{\mathrm{II}}\right)$ to $4.4 \times 10^{9} \mathrm{~s}^{-1}$ $\left(\mathrm{Cu}^{\mathrm{II}}\right) .{ }^{23}$ Molecular dynamics calculations of water exchange on the $3 \mathrm{~d}$ divalent ions between $\mathrm{Mn}$ and $\mathrm{Zn}$ afforded values of $\Delta G^{\ddagger}$ between $17.9(\mathrm{Mn})$ and $32.4(\mathrm{Ni}) \mathrm{kJ} \mathrm{mol}^{-1}$. The predicted $k_{\exp }$ rates were overestimated, due in part to transmission coefficient, $\kappa$, considered as being equal to unity through the transition state. ${ }^{24}$ In a recent molecular dynamics study of reactions at alkali metal ions, the residence time of water coordinated to $\mathrm{Li}^{+}$was calculated to be $191 \mathrm{ps}$, with a $\Delta G^{\ddagger}$ of $17.0 \mathrm{~kJ} \mathrm{~mol}^{-1}$, giving rise to a rate of transition state formation at $2.38 \times 10^{-10} \mathrm{~s}$, and a transmission coefficient of $0.22 .{ }^{25}$ In general, metal complexes and clusters will exhibit metal ligand vibrations between $\sim 300$ and $400 \mathrm{~cm}^{-1}$, and metal-metal stretches between 100 and $200 \mathrm{~cm}^{-1}$. The frequencies of these vibrations lie between 3 and $12 \times 10^{12} \mathrm{~s}^{-1}$, giving a time constant range of $\sim 80-350$ fs.

These values parameterise the time frames for visualising fast chemical reactions in solution. Species may have lifetimes of the order of ps and longer, and the atomic motion (dynamics) of the transitions between species may be 1000 times faster. The transition time of X-ray absorption is much faster than either of these timescales and thus can afford snapshots. Careful experimental design is required to prepare a significant population of the sample molecules to perform the same transition simultaneously.

\section{X-ray spectroscopic structural studies}

\subsection{Beyond steady-state studies}

A general factor is that the acquisition time of a XAFS spectrum for a dilute sample may be of the order of hours, and thus be too slow for the time-resolved studies. This was addressed in the XAFS study of the palladium catalysed Mizoroki-Heck coupling reaction with a pyridine functionalized N-heterocyclic carbene ligand. The pre-catalyst was first formed in situ, and the reactants, butyl acrylate and $p$-bromoacetophenone, injected at the reaction temperature, allowing stages of the reaction to be investigated by rapid cooling and reheating after XAFS measurement. ${ }^{26}$ Such a method could identify the major species present despite long acquisition times, but without a forced cooling process, the time resolution was minutes.

This approach was developed further when investigating Mo halide complexes for ethylene polymerisation by using stopped-flow instrumentation with a mixing time of ms, and a quench time to liquid nitrogen temperature of $\sim 1 \mathrm{~s}^{27}$ The activation and subsequent deactivation mechanism was determined by XAFS analysis showing that the Mo catalyst was firstly methylated by the $\mathrm{AlMe}_{3}$ co-catalyst and subsequently deactivated by Mo particle formation. The same XAFS freezequench technique was used for Sc ethylene polymerization catalysis, where Sc was initially methylated by $\mathrm{AlMe}_{3}$, the Sc-Me then abstracted by a Lewis acid with subsequent coordination of an olefin to Sc centre. ${ }^{28}$ Most recently, probing the active ethylene trimerisation catalyst by the stopped-flow freezequench method allowed identification of an unusual 4-coordinate $\mathrm{Cr}(\mathrm{II})$ complex $\left[(\mathrm{SNS}) \mathrm{Cr}^{\mathrm{II}} \mathrm{Cl}\right]\left\{\mathrm{SNS}=\mathrm{N}\left(\mathrm{CH}_{2} \mathrm{CH}_{2} \mathrm{~S}-\mathrm{Decyl}\right)_{2}{ }_{2}^{-}\right\}$ from the reaction of $\left[\mathrm{CrCl}_{3}\{\mathrm{SN}(\mathrm{H}) \mathrm{S}\}\right]$, with $\mathrm{AlMe}_{3}{ }^{29}$ Without this trapping procedure, the $\mathrm{Cr}(\mathrm{II})$ intermediate would not have been observed, since a slower disproportionation process partially reformed $\mathrm{Cr}(\mathrm{III})$. The rapid-mixing (ms) and quenching (s) however, still allowed a sequence of reactions to transpire before the trapped species has formed. In this case, it is thought to be $\mathrm{N}-\mathrm{H}$ deprotonation, and conjugate-base assistance of chloride loss, transmetalation of a methyl group and a bimolecular reductive elimination of ethane.

\subsection{Combining techniques}

Adding information from complementary technique can be invaluable in differentiating between similar species. Incorporation of UV-visible spectroscopy with stopped-flow XAFS methods, as utilised in the activation of the ethene oligomerisation techniques ${ }^{27}$ is relatively straightforward. Indeed the time resolution properties of energy dispersive XAFS closely match those of a diode-array UV-visible spectrometer providing ms time resolution. In a study of the inner-sphere electron transfer between $\left[\mathrm{IrCl}_{6}\right]^{2-}$ and $\left[\mathrm{Co}(\mathrm{CN})_{5}\right]^{3-}$, the UV-visible data indicated that the reaction studied over the a few seconds by Ir $\mathrm{L}_{\text {III }}$ energy-dispersive XAFS was the breakup of the of the bridged intermediate, $\left[\mathrm{Cl}_{5} \mathrm{Ir}-\mathrm{Cl}-\mathrm{Co}(\mathrm{CN})_{5}\right]^{5-}$, following the electron transfer. ${ }^{30}$

With off-line NMR and EPR studies, the combination of stopped flow XAFS and UV-visible spectroscopies allowed insight into the catalytic cycle for the arylation of imidazole by phenylboronic acid, catalysed by $[\mathrm{Cu}(\mathrm{OH})(\mathrm{TMEDA})]_{2} \mathrm{Cl}_{2}$ $\left(\right.$ TMEDA $=$ tetramethylethylenediamine) ${ }^{31} \mathrm{~A}$ proposed cycle could be tested by binary and ternary mixtures of the reagents. It was evident that imidazole (imidH) formed a new, 4-coordinate mononuclear $\mathrm{Cu}(\mathrm{II})$ complex of the imid ${ }^{-}$anion, [CuCl(imid)(TMEDA)], and addition of $\mathrm{PhB}(\mathrm{OH})_{2}$ resulted in the observation of XANES attributable to $\mathrm{Cu}(\mathrm{I})$ centres after the arylation of the imidazole. Further $\mathrm{PhB}(\mathrm{OH})_{2}$ was required to reoxidise the copper to complete the cycle; all of the stages 
could be followed with second time resolution. A key $\mathrm{Cu}(\mathrm{III})$ intermediate, $[\mathrm{CuX}(\mathrm{Ph})(\mathrm{imid})(\mathrm{TMEDA})]$ could not be observed on this timescale.

\subsection{Pump-probe XAFS}

All the experiments described so far utilise the storage ring source as pseudo-continuous, rather than their true nature of a train of electron pulses, often of $\sim 100$ ps duration, separated by a few ns, rotating every few $\mu$ s. Providing that synchronisation can be achieved with low jitter, and the output from a particular bunch detected without distortion from its neighbours, then the time resolution can be improved from $10^{-3} \mathrm{~s}$ to $10^{-10} \mathrm{~s}$. The appropriate sample preparation method is then a laser pulse, using the storage ring pulse as an X-ray probe.

Chen and Coppens provided an exemplar for pump-probe XAFS in their study on the ${ }^{3}$ MLCT (MLCT $=$ metal-to-ligand charge transfer) state of $\left[\mathrm{Cu}\left(2,9-\mathrm{Me}_{2} \text {-phen }\right)_{2}\right]^{+}$, using a differential acquisition mode (X-ray transient absorption spectroscopy, XTA) to optimise the signal to background ratio. ${ }^{32}$ An example of this is shown in Fig. 3. The $\mathrm{Cu}$ K-edge XANES of the excited state was found to be very similar to the electrochemically generated $\left[\mathrm{Cu}\left(2,9-\mathrm{Me}_{2}-\text { phen }\right)_{2}\right]^{2+}$, strongly supporting the assignment of this as being a MLCT state. In the ground state $\mathrm{Cu}^{\mathrm{I}}$ has $\mathrm{a} \mathrm{d}^{10}$ configuration with a slightly distorted tetrahedral geometry; in the MLCT $\mathrm{Cu}^{\mathrm{II} *}$ complex, $\mathrm{d}^{9}$ centre is susceptible to Jahn-Teller distortion resulting in the excited state having a more flattened tetrahedral geometry (inter-ligand dihedral angle $\sim 57^{\circ}$ ). With these relatively small substituents adjacent to the coordinating nitrogen atoms, there was some evidence from the XANES simulations for the coordination of a molecule of the donor solvent, acetonitrile in the excited state. In our study of $\left[\mathrm{Cu}\left(2,9-{ }^{n} \mathrm{Bu}-3,4,7,8-\mathrm{Me}-\mathrm{phen}\right)_{2}\right]^{+},{ }^{33}$ which was performed using an energy dispersive X-ray spectrometer in an attempt to reduce the real time of the data acquisition, the XANES simulations favoured a $60^{\circ}$ angle and no MeCN binding in an exciplex. Having ${ }^{t} \mathrm{Bu}$ groups on the two carbon atoms adjacent to the nitrogens, in $\left[\mathrm{Cu}\left(2,9-{ }^{t} \mathrm{Bu}-\mathrm{phen}\right)_{2}\right]^{+}$was found to essentially lock the coordination geometry as being pseudotetrahedral, ${ }^{34}$ and this is a likely cause of the long lifetime of the ${ }^{3}$ MLCT state.

The majority of synchrotron storage ring sources provide an $\mathrm{X}$-ray pulse of $100 \mathrm{ps}$, and this marks the normal highest time

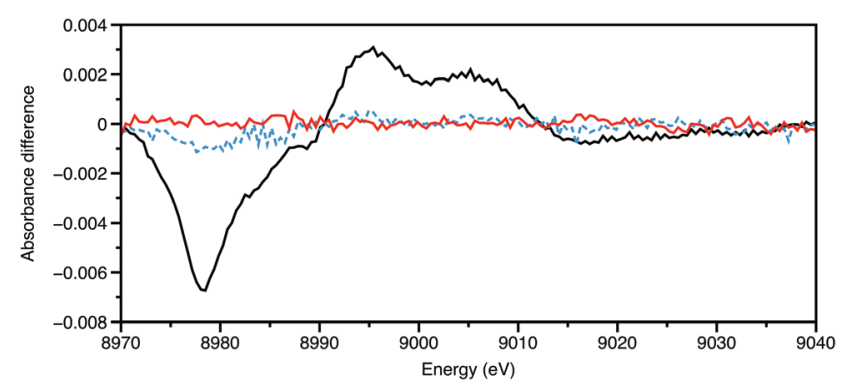

Fig. $3 \mathrm{Cu}$ K-edge XTA of $\left[\mathrm{Cu}\left(2,9-\mathrm{Me}_{2}-\text { phen }\right)_{2}\right]^{+}$in $\mathrm{MeCN}(20 \mathrm{mM})$ showing the data $5 \mathrm{~ns}$ before laser pulse $(450 \mathrm{~nm})(\mathrm{red})$, during the pulse (black), and $5 \mathrm{~ns}$ after (blue). Data recorded on ID24 of the ESRF. resolution of such a source. Chen and co workers ${ }^{35}$ have studied $\mathrm{Ni}(\mathrm{II})($ tetramesitylporphyrin) by photoactivated XTA. This $\mathrm{d}^{8}$ complex has a distorted square-planar geometry with a vacant $3 \mathrm{~d}_{x^{2}-y^{2}}$ orbital. Upon photoexcitation, a one electron transition from the ligand $\pi$ to a $\pi^{*}$ orbital on the porphyrin with a subsequent transfer from the $\pi^{*}$ to the empty $3 d_{x^{2}-y^{2}}$, and there is an associated transfer of an electron from the $3 \mathrm{~d}_{z^{2}}$ back into the empty hole in the $\pi$ orbital, all within 20 ps of the excitation. ${ }^{36}$ This excited state has a lifetime of $\sim 200 \mathrm{ps}$ and was observed by Ni K-edge XAFS within 100 ps. The electron transfer resulted in longer $\mathrm{Ni}-\mathrm{N}$ and $\mathrm{Ni}-\mathrm{C}_{\alpha}$ distances $(0.08 \AA)$ in the excited state. The transfers generated a singly occupied $3 \mathrm{~d}_{z^{2}}$ orbital, shown to promote the binding of an axial ligand that was followed by the 100 ps X-ray pulse structure.

Photo-excited myoglobin studies have also been undertaken using fast XAFS. ${ }^{36}$ This class of biological compounds have many uses including electron transfer, catalytic oxidation and reduction, and for binding of diatomics such as $\mathrm{O}_{2}$, NO and CO for transport and signalling. ${ }^{37}$ Chergui has reported a detailed study of myoglobin complexes in physiological conditions, ${ }^{38}$ and demonstrated that Fe K-edge XANES of an excited state of the protein could be recorded on a $2 \mathrm{mM}$ solution. ${ }^{39}$ In further XTA studies, Chen ${ }^{40}$ collected XAFS of the CO derivative every $100 \mathrm{ps}$, which exhibited a significant change in the Fe K-edge XANES. This showed that photo-dissociation was complete within the first $100 \mathrm{ps}$ and lasted for at least $47 \mu \mathrm{s}$. The EXAFS analysis revealed the complex exhibited a square pyramidal geometry, where the $\mathrm{Fe}-\mathrm{N}_{\text {por }}$ bonds were extended by $0.06 \AA$.

\section{Ultrafast X-ray techniques and dynamics}

The results from storage ring pump-probe XAFS have given considerable structural insights on the events occurring after 100 ps of the exciting pulse; in this time regime, they augment optical methods considerably. However, these sources in their standard form cannot serve in the same way for the primary photo-events. Alternatives are available, ${ }^{3}$ including operation of the storage ring specifically to deliver narrow pulses with low current (low alpha mode), which may afford sub 10 ps time resolution. However, to move from kinetic to dynamic studies, the time resolution will need to be sub $100 \mathrm{fs}$. This can be achieved either by deflecting a thin slice of an electron bunch with a fs laser or from an X-ray electron laser (X-FEL). ${ }^{41}$

The very low X-ray fluxes from sliced sources renders all experiments to be immensely challenging. ${ }^{41}$ Nevertheless, some intriguing results have emerged from them. An example is the changes in structure around iodide in aqueous solution following excitation with visible light $(400 \mathrm{~nm})$, for which the earliest species observable was a $\mathrm{I}^{0}\left(\mathrm{H}_{2} \mathrm{O}\right)$ complex within the solvent cage. $^{42}$

The opposite circumstance arises from an X-FEL, namely damaging X-ray fluxes $\left(\sim 10^{12}\right.$ photons per pulse) with shot-to- 
shot intensity variations. The bandwidth of the X-ray source is provided by undulator radiation, which is of the order of $50 \mathrm{eV}$ at $10 \mathrm{keV}$, thus presently excluding EXAFS structure analysis. At the LCLS facility at Stanford, using a liquid jet, 190 fsresolved Fe K-edge XANES $(\sim 40 \mathrm{eV})$ using a double-crystal monochromator were recorded on an aqueous solution of $\left[\mathrm{Fe}(\text { bipy })_{3}\right]^{2+}\left(50 \mathrm{mM}\right.$, bipy $=2,2^{\prime}$ bipyridine $) .{ }^{43}$ Due to the statedependence of the XANES features, the time constant for the formation of the ${ }^{5} \mathrm{~T}_{2}$ high spin excited state could be estimated at $\sim 160$ fs.

An alternative approach then to acquire more extensive $\mathrm{X}$-ray spectroscopic information has its parallels in the optical region with Raman spectroscopy. A jet of glycerol-water has been used to provide a medium for studying Mn complexes by energy-dispersive (von Hamos) X-ray emission spectroscopy which is adapted well for shot-to-shot variations in the X-ray properties. ${ }^{44}$ An oxidation state dependence was evident in the $\mathrm{K} \beta$ emission, and this technique was later applied to investigating the oxidation state changes within the $\mathrm{Mn}_{4} \mathrm{CaO}_{5}$ cluster of photosystem II. $^{45}$ Even after a sequence of laser pulses, no evidence for a $\mathrm{Mn}^{\mathrm{V}}$ site was apparent up to $250 \mu \mathrm{s}$ after the pulses, instead occupying states between $\mathrm{Mn}_{4}^{\mathrm{IV}}$ and $\mathrm{Mn}^{\mathrm{III}}{ }_{3}^{-}$ $\mathrm{Mn}^{\mathrm{IV}}$. The diffraction component of this report revealed an absence of $\mathrm{O}-\mathrm{O}$ bond formation over that $250 \mu$ s period too.

Inelastic scattering approach has progressed a stage further at the soft X-ray laser FLASH (Hamburg), which allowed a study of the photochemistry of $\mathrm{Fe}(\mathrm{CO})_{5}$ using the $\mathrm{Fe} \mathrm{L}_{\mathrm{III}}$ absorption edge. ${ }^{46}$ The emission spectrometer was used to record RIXS spectra at very high time resolution, such that a feature could be distinguished from those due to the solvated $\mathrm{Fe}(\mathrm{CO})_{5}$ itself and assigned to $\mathrm{Fe}(\mathrm{CO})_{4}$. Using that, the build up of the coordinatively unsaturated intermediate could indeed be monitored.

An alternative use of the dispersive emission spectrometer is to probe the unoccupied states (like XANES) by high-energy resolution off-resonant spectroscopy (HEROS). ${ }^{47}$ This uses a single probe energy, which is set lower (20-30 eV) than that of the absorption edge and so has anti-Stokes characteristics. It is also complementary to XES, for which the probe energy is set within the XANES region and which probes occupied states. This approach has been tested at LCLS, using $\mathrm{Cu}$ and $\mathrm{CuO}$ as samples, and has given promising results. ${ }^{48}$

\section{Conclusions}

The developments in light sources, X-ray spectroscopic measurements and theory have been very considerable over the last decade. On a synchrotron storage ring source now, there is a clear capability for investigating secondary processes after an initial excitation pulse. These can include fluorescence behaviour, but also thermal reactions from photo-induced transients. Much greater chemical speciation is feasible now, due, in large measure, to the development of emission spectroscopy and inelastic scattering techniques. Examining the primary light-induced processes remains a considerable chal- lenge, but recent results with the first X-ray free electron lasers show that this too is becoming viable. The use of X-ray pulses ( $\sim 20 \mathrm{fs}$ ) of shorter duration than atomic motion allows X-ray data to be acquired before the coulombic explosion that destroys the irradiated region of the sample, and thus X-ray diffraction is viable as a single shot procedure. That timescale, however, still allows multiphoton events. Some, like multiple ionisation of core orbitals may be problematical for sampling, as observed for $\mathrm{H}_{2} \mathrm{~S} .{ }^{49}$ However, others point to new technique opportunities involving nonlinear processes. ${ }^{50} \mathrm{~A}$ two-photon absorption, using $5.6 \mathrm{keV}$ radiation was used to pump above the K-edge of germanium (11.103 keV), and the event was detected by measuring the $K \alpha_{1}$ and $K \alpha_{2}$ emissions. One may envisage two-colour versions that might provide inter-element correlations of excited states. In this second century of X-ray science, new classes of experiments are opening up. The challenge for the experimental chemist is to design the incisive experiments, and to love the problem enough to see it through!

\section{Acknowledgements}

We wish to thank EPSRC for funding to the Dynamic Structural Science (DySS) consortium at the Research Complex at Harwell (EP/ I01974X/1).

\section{References}

1 M. Gao, C. Lu, H. Jean-Ruel, L. C. Liu, A. Marx, K. Onda, S.-y. Koshihara, Y. Nakano, X. Shao, T. Hiramatsu, G. Saito, H. Yamochi, R. R. Cooney, G. Moriena, G. Sciaini and R. J. D. Miller, Nature, 2013, 496, 343-346.

2 M. A. Newton, A. J. Dent and J. Evans, Chem. Soc. Rev., 2002, 31, 83-95.

3 J. Evans, Phys. Chem. Chem. Phys., 2006, 8, 3045-3058.

4 W. H. Bragg, Proc. R. Soc., 1913, 89, 246-248.

5 M. de Broglie, C. R Chim., 1913, 157, 924-926.

6 H. G. J. Moseley, Philos. Mag., 1913, 26, 1024-1034; H. G. J. Moseley, Philos. Mag., 1914, 27, 703-713.

7 H. Fricke, Phys. Rev., 1920, 20, 201-215.

8 E. A. Stern, Phys. Rev. B: Solid State, 1974, 10, 3027-3037.

9 EXCURV(9.301) program: N. Binsted, in STFC Daresbury Laboratory computer program, 1998; FEFF programs: M. Newville, J. Synchrotron Radiat., 2001, 8, 322-324; B. Ravel and M. Newville, J. Synchrotron Radiat., 2005, 12, 537-541.

10 K. Hämäläinen, D. P. Siddons, J. B. Hastings and L. E. Berman, Phys. Rev. Lett., 1991, 67, 2850-2853.

11 P. Glatzel and U. Bergmann, Coord. Chem. Rev., 2005, 249, 65-95.

12 FEFF9 program: J. J. Rehr, J. J. Kas, M. P. Prange, A. P. Sorini, Y. Takimoto and F. Vila, C. R. Phys., 2009, 10, 548-559; J. J. Rehr, J. J. Kas, F. D. Vila, M. P. Prange and K. Jorissen, Phys. Chem. Chem. Phys., 2010, 12, 5503-5513. 
13 MXAN program: M. Benfatto and S. Della Longa, J. Synchrotron Radiat., 2001, 8, 1087-1094.

14 K. Hermann, L. G. M. Pettersson, M. E. Casida, C. Daul, A. Goursot, A. Koester, E. Proynov, A. St-Amant and D. R. Salahub. Contributing authors: V. Carravetta, H. Duarte, C. Friedrich, N. Godbout, M. Gruber, J. Guan, C. Jamorski, M. Leboeuf, M. Leetmaa, M. Nyberg, S. Patchkovskii, L. Pedocchi, F. Sim, L. Triguero and A. Vela, StoBe-deMon program, http://www.fhi-berlin.mpg. de/KHsoftware/StoBe.

15 The ORCA program system: F. Neese, Wiley Interdiscip. Rev.: Comput. Mol. Sci., 2012, 2, 73-78.

16 X. Zhang, S. E. Canton, G. Smolentsev, C.-J. Wallentin, Z. Liu, Q. Kong, K. Attenkofer, A. B. Strickrath, M. W. Mara, L. X. Chen, K. Wärnmark and V. Sundström, J. Am. Chem. Soc., 2014, 136, 8804-8809.

17 G. Capano, T. J. Penfold, N. A. Besley, C. J. Milne, M. Renhard, H. Rittmann-Frank, P. Glatzel, R. Abela, U. Rothlisberger, M. Chergui and I. Tavernellis, Chem. Phys. Lett., 2013, 580, 179-184.

18 N. Leidel, P. Chernev, K. G. V. Havelius, L. Schwartz, S. Ott and M. Haumann, J. Am. Chem. Soc., 2012, 134, 1414214147.

19 M. Lundberg, T. Kroll, S. DeBeer, U. Bergmann, S. A. Wilson, P. Glatzel, D. Nordlund, B. Hedman, K. O. Hodgson and E. I. Solomon, J. Am. Chem. Soc., 2013, 135, 17121-17134.

20 O. M. Roscioni, J. M. Dyke and J. Evans, J. Phys. Chem. C, 2013, 117, 19464-19470.

21 J. C. Swarbrick, T.-C. Weng, K. Schulte, A. N. Khlobystov and P. Glatzel, Phys. Chem. Chem. Phys., 2010, 12, 9693-9699.

22 S. A. Bartlett, J. Moulin, M. Tromp, G. Reid, A. J. Dent, G. Cibin, D. S. McGuinness and J. Evans, ACS Catal., 2014, 4, 4201-4204.

23 R. J. Deeth and K. Randell, Inorg. Chem., 2008, 47, 73777388, and references therein.

24 H. Loffler, A. M. Mohammed, Y. Inada and S. Funahashi, J. Comput. Chem., 2006, 27, 1944-1949.

25 H. V. R. Annapureddy and L. X. Dang, J. Phys. Chem. B, 2014, 118, 8917-8927.

26 S. G. Fiddy, J. Evans, T. Neisius, M. A. Newton, N. Tsoureas, A. A. D. Tulloch and A. A. Danopoulos, Chem. - Eur. J., 2007, 13, 3652-3659.

27 S. A. Bartlett, P. P. Wells, M. Nachtegaal, A. J. Dent, G. Cibin, G. Reid, J. Evans and M. Tromp, J. Catal., 2011, 284, 247-258.

28 S. A. Bartlett, G. Cibin, A. J. Dent, J. Evans, M. J. Hanton, G. Reid, R. P. Tooze and M. Tromp, Dalton Trans., 2013, 42, 2213-2223.

29 S. A. Bartlett, J. Moulin, M. Tromp, G. Reid, A. J. Dent, G. Cibin, D. S. McGuinness and J. Evans, ACS Catal., 2014, 4, 4201-4204.

30 S. Diaz-Moreno, D. T. Bowron and J. Evans, Dalton Trans., 2005, 3814-3817.

31 M. Tromp, G. P. F. van Strijdonck, S. S. van Berkel, A. van der Hoogenband, M. C. Feiters, B. de Bruin, S. G. Fiddy,
A. M. J. van der Eerden, J. A. van Bokhoven, P. W. N. M. van Leeuwen and D. C. Koningsberger, Organometallics, 2010, 29, 3085-3097.

32 L. X. Chen, G. B. Shaw, I. Novozhilova, T. Liu, G. Jennings, K. Attenkofer, G. J. Meyer and P. Coppens, J. Am. Chem. Soc., 2003, 125, 7022-7034.

33 M. Tromp, A. J. Dent, J. Headspith, T. L. Easun, X.-Z. Sun, M. W. George, O. Mathon, G. Smolentsev, M. L. Hamilton and J. Evans, J. Phys. Chem. B, 2013, 117, 7381-7387.

34 N. A. Gothard, M. W. Mara, J. Huang, J. M. Szarko, B. Rolcynski, J. V. Lockard and L. X. Chen, J. Phys. Chem. A, 2012, 116, 1984-1992.

35 L. X. Chen, X. Y. Zhang, E. C. Wasinger, K. Attenkofer, G. Jennings, A. Z. Muresan and J. S. Lindsey, J. Am. Chem. Soc., 2007, 129, 9616-9618; X. Y. Zhang, E. C. Wasinger, A. Z. Muresan, K. Attenkofer, G. Jennings, J. S. Lindsey and L. X. Chen, J. Phys. Chem. A, 2007, 111, 11736-11742.

36 M. L. Shelby, M. W. Mara and L. X. Chen, Coord. Chem. Rev., 2014, 277-278, 291-299.

37 U. B. Hendgen-Cotta, U. Flögel, M. Kelm and T. Rassaf, J. Exp. Biol., 2010, 213, 2734-2740; U. B. Hendgen-Cotta, M. Kelm and T. Rassaf, Free Radicals Biol. Med., 2014, 73, 252-259.

38 F. A. Lima, T. J. Penfold, R. M. van der Veen, M. Reinhard, R. Abela, I. Tavernelli, U. Rothlisberger, M. Benfatto, C. J. Milne and M. Chergui, Phys. Chem. Chem. Phys., 2014, 16, 1617-1631.

39 F. A. Lima, C. J. Milne, D. C. V. Amarasinghe, M. H. Rittmann-Frank, R. M. van der Veen, M. Renhard, V.-T. Pham, S. Karlsson, S. L. Johnson, D. Grolimund, C. Borca, T. Huthwelker, M. Janousch, F. van Mourik, R. Abela and M. Chergui, Rev. Sci. Instrum., 2011, 82, 063111.

40 M. W. Mara, M. Shelby, A. Stickpath, M. Harpham, J. Huang, X. Y. Zhang, B. M. Hoffman and L. X. Chen, J. Phys. Chem. B, 2013, 117, 14089-14098.

41 C. J. Milne, T. J. Penfold and M. Chergui, Coord. Chem. Rev., 2014, 277-278, 44-68.

42 V.-T. Pham, T. J. Penfold, R. M. van der Veen, F. Lima, A. El Nahha, S. L. Johnson, P. Beard, R. Abela, C. Bressler, I. Tavernelli, C. J. Milne and M. Chergui, J. Am. Chem. Soc., 2011, 133, 12740-12748.

43 H. T. Lemke, C. Bressler, L. X. Chen, D. M. Fritz, K. J. Gaffney, A. Galler, W. Gawelda, K. Haldrup, R. W. Hartsock, H. Ihee, J. Kim, K. H. Kim, J. H. Lee, M. M. Nielson, A. B. Strickrath, W. Zhang, D. Zhu and M. Cammarata, J. Phys. Chem. A, 2013, 117, 735-740.

44 R. Alonso-Mori, J. Kern, R. J. Gildea, D. Sokaras, T.-C. Weng, B. Lassalle-Kaiser, R. Tran, J. Hattne, H. Laksmono, J. Hellmich, C. Glöckner, N. Echols, R. G. Sierra, D. W. Schafer, J. Sellberg, C. Kenney, R. Herbst, J. Pines, P. Hart, S. Herrmann, R. W. GrosseKunstleve, M. J. Latimer, A. R. Fry, M. M. Messerschmidt, A. Miahnahri, M. M. Seibert, P. H. Zwart, W. E. White, P. D. Adams, M. J. Bogan, S. Boutet, G. J. Williams, 
A. Zouni, J. Messinger, P. Glatzel, N. Sauter, V. K. Yachandra, J. Yano and U. Bergmann, Proc. Natl. Acad. Sci. U. S. A., 2012, 109, 19103-19107.

45 J. Kern, R. Tran, R. Alonso-Mori, S. Koroidov, N. Echols, J. Hattne, M. Ibrahim, S. Gul, H. Laksmono, R. G. Sierra, R. J. Gildea, G. Han, J. Hellmich, B. Lassalle-Kaiser, R. Chatterjee, A. S. Brewster, C. A. Stan, C. Glöckner, A. Lampe, D. DiFiore, D. Milathianaki, A. R. Fry, M. M. Seibert, J. E. Koglon, E. Gallo, J. Uhig, D. Sokaras, T.-C. Weng, P. H. Zwart, D. E. Skinner, M. J. Bogan, M. Messerschmidt, P. Glatzel, G. J. Williams, S. Boutet, P. D. Adams, A. Zouni, J. Messinger, N. K. Sauter, U. Bergmann, J. Yano and V. K. Yachandra, Nat. Commun., 2014, 5, 4371.

46 P. Werner, M. Beye, F. de Groot, S. Düsterer, K. Gaffney, S. Grübel, R. Hartsock, F. Hennies, I. Josefsson, B. Kennedy, K. Kunnus, T. Leitner, T. Mazza, M. Meyer, D. Nordlund, M. Odelius, W. Quevedo, P. Radcliffe,
I. Rajkovic, B. Schlotter, M. Scholz, E. Schreck, E. Suljoti, S. Techert, J. Turner, C. Weniger, W. Zhang and A. Föhlisch, EPJ Web Conf., 2013, 41, 05025.

47 W. Blachucki, J. Szlachetko, J. Hoszowska, J.-C. Dousse, Y. Kayser, M. Nachtegaal and J. Sá, Phys. Rev. Lett., 2014, 112, 173003.

48 J. Szlachetko, C. J. Milne, J. Hoszowska, J.-C. Dousse, W. Bachucki, J. Sà, Y. Kayser, M. Messerschmidt, R. Abela, S. Boutet, C. David, G. Williams, M. Pajek, B. D. Patterson, G. Smolentsev, J. A. van Bokhoven and M. Nachtegaal, Struct. Dyn., 2014, 1, 021101.

49 B. F. Murphy, L. Fang, M.-H. Chen, J. D. Bozek, E. Kukk, E. P. Kanter, M. Messerschmidt, T. Osipov and N. Berrah, Phys. Rev. A, 2012, 86, 053423.

50 K. Tamasaku, E. Shigemasa, Y. Inubushi, T. Katayama, K. Sawada, H. Yumoto, H. Ohashi, H. Mimura, M. Yabishi, K. Yamauchi and T. Ishilawa, Nat. Photonics., 2014, 8, 313-316. 